\title{
Do papel das relações entre palavra e imagem nas questões de gênero
}

Leonardo Motta Tavares 
Nestes últimos anos de criação visual e produção teórica ${ }^{1}$ centrada nas relações entre a palavra e a imagem, tenho me deparado com problematizações que interligam este tema a outras esferas que até então me pareciam fora de alcance de sua espinha dorsal. $O$ interesse explícito em meu projeto de pesquisa de Doutorado era localizar os pontos de fusão, a partir da análise dos pontos de distanciamento entre as artes visuais e a literatura. Desde o começo da pesquisa, no entanto, tenho percebido a necessidade de retornar, irremediavelmente, para a homologia estrutural, e analisar o que disseram os adeptos da não separação entre as artes, mas, mais fortemente, debruçar-me sobre aqueles que insistiram na sua diferenciação.

Todos os autores que tratam dos diálogos interartes sempre retornam ao Laocoonte ou sobre as fronteiras da pintura e da poesia (1766), de Gotthold Ephraim Lessing $^{2}$, o autor alemão que dá a esta questão o enfoque da relação entre tempo e espaço, ou seja, aborda as diferenças e aproximações entre as artes do tempo e as artes do espaço, tendo como protagonistas a poesia e a pintura. O que eu nunca tinha pensado, e que o norte-americano W. J. T Mitchell esclarece em Iconology: Image, Text, Ideology (1986), é o quanto o problema da divisão entre as duas artes está profundamente relacionado às noções históricas do masculino e do feminino e o quanto as tentativas (da arte e da literatura modernas) de cancelamento das fronteiras interartes produz, em todas as suas investidas contra a tradição, uma espécie de mal estar social.

A arte dita subversiva, libertária, que não se refreia ao regulamento da tradição, é sempre a presença desse feminino, considerado obscuro, perigoso e incompreensível, imiscuindo-se nas formas nítidas, reguladas e imediatas do masculino. Para Lessing, as diferenças fundamentais entre a poesia e a pintura situam no escopo da primeira as noções de tempo, expressão, mente, eloquência, sublime, e masculino, enquanto são relegadas à segunda as noções de espaço, imitação, corpo, silêncio, beleza e feminino (LESSING apud MITCHELL, 1986, p. 110). Ele vai além, postulando que as ameaças à pureza dos gêneros, ou seja, as violações das esferas da pintura dentro da poesia, e vice-versa, geram o que chamamos de moderno, dentro do qual habitam as noções de adultério em oposição à honestidade do "gênero puro", do monstruoso em oposição à visualidade dos corpos belos, da mãe em oposição ao pai.

As três imagens que apresento, ao final destas considerações, foram produzidas - em consonância com todo o meu corpo de trabalho - como investigações das relações entre palavra e imagem. São colagens que lidam com as imposições de gênero e brincam com os limites impostos também às circunscrições do verbal e do visual.

\footnotetext{
1 Atualmente desenvolvo uma tese de Doutorado intitulada palavra = imagem: uma poética das relações entre o visível e o legível, na linha de pesquisa Poéticas Contemporâneas, do Programa de Pós-Graduação em Arte da Universidade de Brasilia (PPG-Arte/UnB), sob orientação da Profa. Dra. Nivalda Assunção de Araújo.

2 Gotthold Ephraim Lessing (Kamenz, Alemanha, 22 de janeiro de 1729 - Braunschweig, Alemanha, 15 de fevereiro de 1781).
} 
Mitchell chama a atenção para o fato de que o problema da relação palavra e imagem nunca foi uma questão puramente teórica, mas que sempre refletiu as relações sociais, políticas, psicológicas e ideológicas, ao passo que os gêneros (na acepção de categorias formais da arte e na acepção de categorias humanas), jamais são meras definições técnicas, mas sim atos de exclusão e apropriação.

O feminino, compreendido socialmente (e na iconologia) como fonte do falso, do adúltero, do obscuro, do perigoso, do sedutor, do metafórico e do mítico, sempre esteve por trás do horror dos iconoclastas, e, portanto, toda vez que a arte se empapa de tudo aquilo que é subterraneamente relacionado ao feminino provoca mal estar. Lessing prefere a poesia à pintura porque para ele toda a arte que se afasta da verdade (compreendida como pureza e rigor) e se aproxima demais do prazer deve ser regulada, controlada por leis do homem. Mitchell lembra que o pai de Lessing foi o autor de um texto chamado De non commutando sexus habitu, que versa sobre "a impropriedade do uso de roupas masculinas por mulheres e do uso de roupas femininas por homens" (MITCHELL, 1986, p. 111), e que as leis de gênero, nas duas acepções comentadas, estão interligadas uma à outra, mas também ao contexto histórico. A exemplo disso, nas vanguardas do começo do século $X X$, quando a palavra começa a invadir as artes visuais (em Pablo Picasso, em Kurt Schwitters, no futurismo e no Dada) e quando a imagem passa a fazer parte da literatura, não como ilustração, mas como componente a ocupar o mesmo platô hierárquico (Mallarmé e os que vieram depois), paralelamente ocorre uma contravenção no que diz respeito exatamente ao modo de se vestir, e o masculino e o feminino então se veem confundidos. Não é à toa que é precisamente nesta época que nasce a Rrose Sélavy de Marcel Duchamp, mescla de feminino e masculino que é também o suprassumo da cópula entre o jogo de linguagem e a imagem.

Esta confusão, que sempre gerou, para a arte, liberdade e possibilidades de novos caminhos, consiste em desestabilização e constrangimento à população que não tem a arte como uma presença cotidiana, mas que sabe, ou pressente, que a liberdade artística e o rompimento das regras da tradição acabam por se espraiar também para as relações sociais. Todo o movimento social conservador, em contrapartida, não deixa de se ocupar da arte, hoje se voltando especialmente à arte que se envereda para a confluência entre as noções de arte e vida, a fim de tentar reposicioná-la às suas antigas classificações e convenções "ideais", e todas estas convenções ideais estão sempre em consonância com as noções atribuídas ao masculino.

O feminino, portanto, ou a noção do que é o feminino, continua sendo a causa da perturbação do totalitário, o que me leva a constatar que a arte é sim muito importante até para quem não vê arte, na medida em que os seus detratores ou os que a ignoram se voltam imediatamente para atacá-la toda vez que percebem que ela não se subordina, já há mais de cem anos, ao classificatório do masculino-feminino, preferindo burlar as separações e as determinações de gênero. A arte insubordinada às leis do homem representa um fenômeno perigoso para o cidadão conservador; nas palavras de Lessing: "as artes plásticas, pela inevitável influência que exercitam no caráter de uma nação, têm o poder de causar certo efeito que demanda a atenção 
cuidadosa da lei" (LESSING apud MITCHELL, 1986, p. 108). É por isto que o nosso modelo social, taxonômico até a raiz, corre sempre o risco do totalitarismo: para o totalitário uma obra de arte não pode ser ao mesmo tempo imagem e texto, poesia e pintura, arte e vida, performance e crítica, teoria e poética, não pode ser ao mesmo tempo completamente eloquente e muda, incompreensível e dizer muito, resumindo: a arte aos olhos do conservador não têm o direito de ser um ornitorrinco.

\section{Referências}

LESSING, G. E. Laocoonte ou sobre as fronteiras da pintura e da poesia: com esclarecimentos ocasionais sobre diferentes pontos da história da arte antiga. Introdução, tradução e notas Márcio Seligmann-Silva. São Paulo: Iluminuras, 1998.

MITCHELL, W. J. T. Iconology: Image, Text, Ideology. Chicago: The University of Chicago Press, 1986. 
Uma tarde cor-de-rosa...

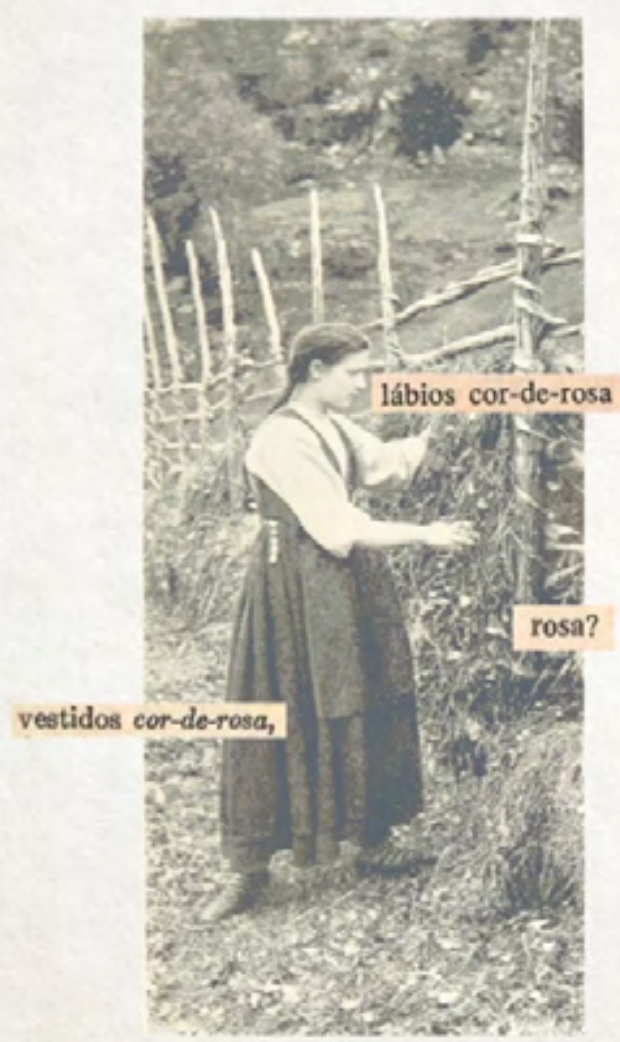

tristeza

violeta

Fig 1: Léo Tavares, Tristeza Violeta, série Contos, Fábulas, Horrores. Colagem, $21.0 \times 29.7 \mathrm{~cm} .2017$. 


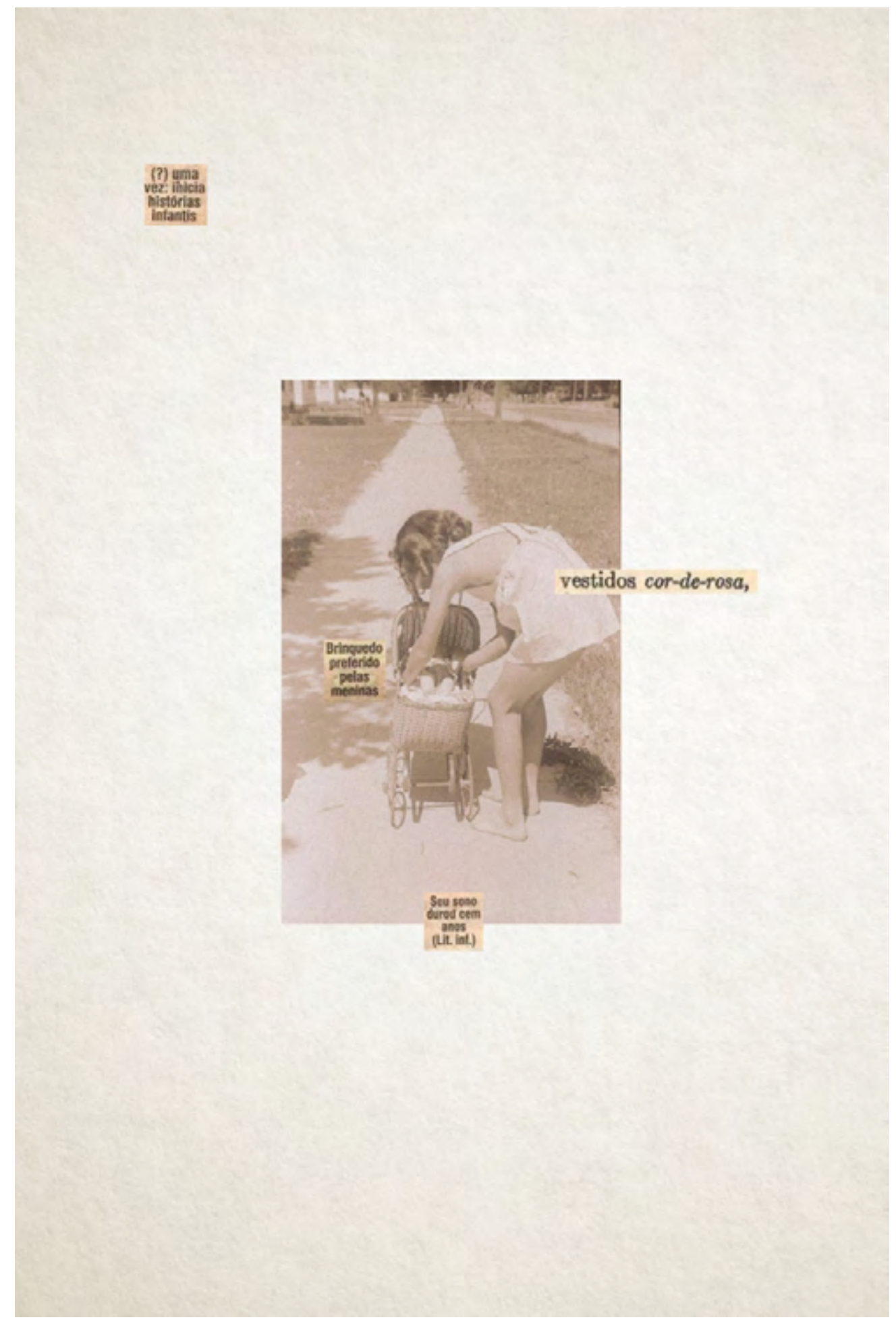

Fig. 2: Léo Tavares, Seu sono durou cem anos, série Contos, Fábulas, Horrores Colagem, $21.0 \times 29.7 \mathrm{~cm} .2017$. 


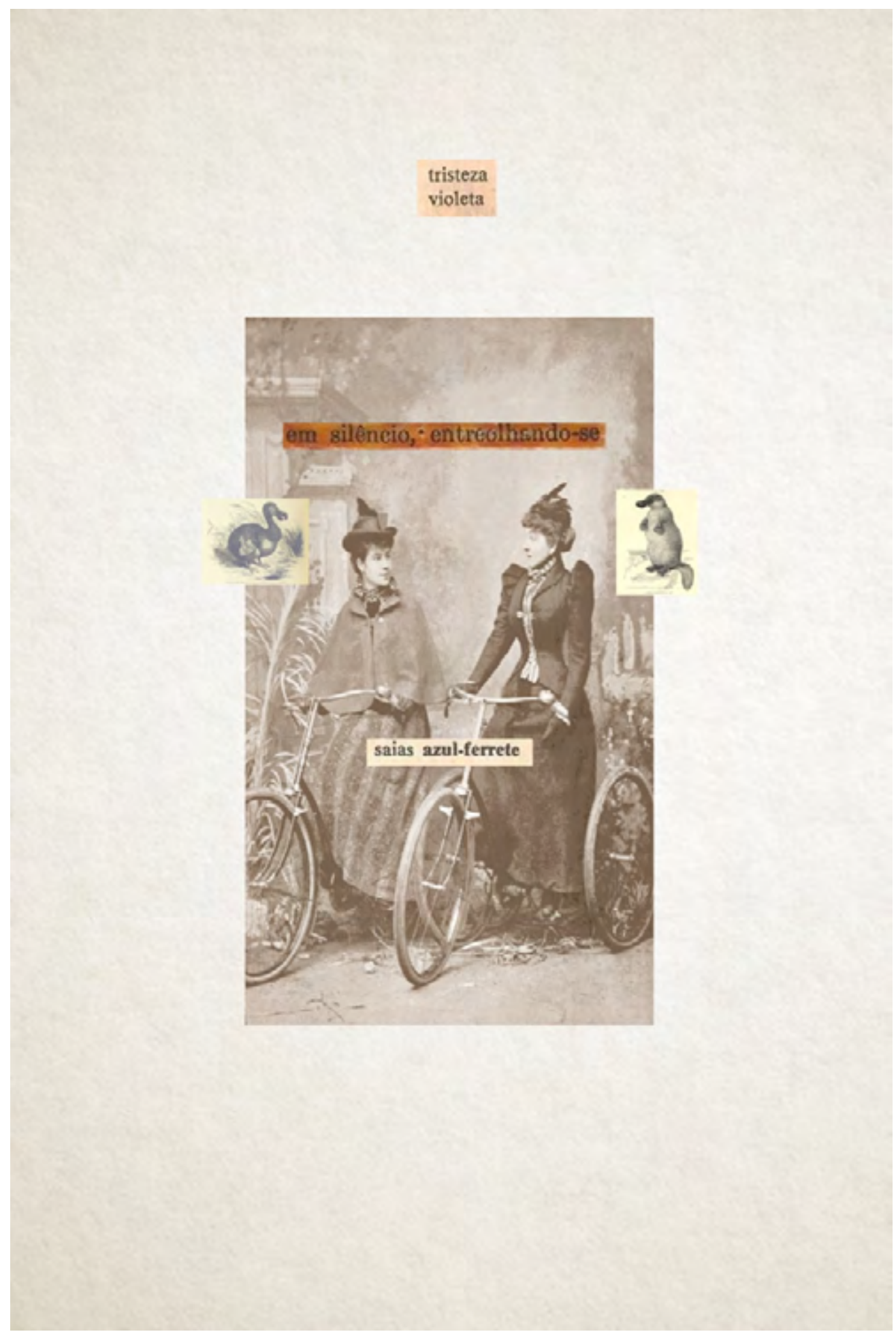

Fig. 3: Léo Tavares, O dodo e o ornitorrinco, série Contos, Fábulas, Horrores. Colagem, 21.0 X 29.7 cm. 2017. 


\section{PAL Í NDROMO}

